\title{
Changes in youth mental health, psychological wellbeing, and substance use during the COVID-19 pandemic: A rapid review
}

Camille Zolopa (BA), ${ }^{1}$ Jacob A. Burack (PhD), ${ }^{2}$ Roisin M. O'Connor (PhD), ${ }^{3}$ Charlotte Corran $(\mathrm{MA}),{ }^{3}$ Jessica Lai (MEd), ${ }^{2}$ Emiliana Bomfim (PhD), ${ }^{2}$ Sarah DeGrace (MSc), ${ }^{4}$ Julianne Dumont $(\mathrm{MA}){ }^{3}$ Sarah Larney $(\mathrm{PhD}),{ }^{1,5^{*}}$ Dennis C. Wendt $(\mathrm{PhD})^{2^{*}}$

${ }^{1}$ Centre de Recherche du Centre Hospitalier de l'Université de Montréal (CR-CHUM), 900 rue SaintDenis, Montréal, QC, H2X 0A9, Canada

${ }^{2}$ Department of Educational \& Counselling Psychology, McGill University, 845 rue Sherbrooke O, Montreal, QC, H3A 0G4, Canada

${ }^{3}$ Department of Psychology, Concordia University, 7141 Sherbrooke St. West Montreal, QC H4B 1R6

${ }^{4}$ Department of Psychiatry, Dalhousie University, 5909 Veterans' Memorial Lane, 8th Floor, Abbie J. Lane Memorial Building, QEII Health Sciences Centre, Halifax, NS, Canada B3H 2E2

${ }^{5}$ Department of Family Medicine and Emergency Medicine, Université de Montréal, 2900 boulevard d'Edouard Montpetit, Montreal, QC, H3T 1J4, Canada

*Joint senior author

Corresponding author: Dr. Sarah Larney

Email: sarah.larney@umontreal.ca

Telephone: +14385304548

Postal address: 900 rue Saint-Denis, porte R6-432, Montréal, QC H2X 0A9, Canada

Running head: Youth mental health, substance use during COVID-19

Ethical approval was not required as this is a review paper.

Conflicts of interest: The authors have declared that they have no competing or potential conflicts of interest. 


\begin{abstract}
Background: The focus of this review was to assess changes in youth mental health, psychological wellbeing, or substance use, as well as changes or disruptions to the delivery of mental health or substance use services for young people during the COVID-19 pandemic.
\end{abstract}

Method: We conducted a rapid review of the literature on our outcomes of interest among youth (age $<=25$ ) in the context of the COVID-19 pandemic. Primary studies and systematic reviews on change were eligible for inclusion. Searches were conducted in PubMed and Embase in May 2021, and two reviewers screened studies for inclusion. We report results using a narrative synthesis.

Results: We included 156 primary publications. A variety of methods were used to assess change, including prospective assessment of longitudinal cohorts, retrospective recall by participants in cross-sectional and qualitative studies, and comparison of peri-pandemic data to pre-pandemic normative values. Publications regarding mental health $(n=121)$ and psychological wellbeing $(n=26)$ generally indicated poor outcomes during the pandemic period. Publications on substance use $(n=41)$ revealed overall declines or unchanged patterns of use, though certain groups reported increased or problematic use. Studies of service delivery $(n=11)$ indicated a generally positive reception for helplines and telehealth, although some youth experienced difficulties accessing mental health services.

Conclusions: The evidence indicates negative impacts of the COVID-19 pandemic on young people's mental health, although declines in alcohol and nicotine use were also found. Services will need to continue to adapt as the pandemic progresses, particularly to support disadvantaged youth who lack access to telehealth resources. 


\section{Key Practitioner Message:}

What is known?

- The COVID-19 pandemic has disrupted the lives of young people around the world. Life stressors may engender or exacerbate mental health or substance use problems among youth, particularly among vulnerable subgroups of youth.

- Despite plentiful reports regarding the prevalence of these issues during the pandemic, it was unclear if or how youth mental health, psychological wellbeing, and substance use had changed during this period.

\section{What is new?}

- The COVID-19 pandemic has negatively affected youth mental health in many settings. While some youth reduced their substance use during this period, other young people have increased their substance use frequency or quantity.

- Telehealth offerings are generally positively received, but require access to space and technology resources that disadvantaged youth may lack.

What is significant for clinical practice?

- Clinicians that work with youth should be aware of the negative mental health impacts during the pandemic period. Services will need to adapt their offerings to target particularly marginalized youth, who may have difficulty accessing telehealth technology.

- Further research is needed to address the use of illicit substances among youth during this period.

Keywords: youth; children; adolescents; mental health; substance use; COVID-19 


\section{Changes in youth mental health, psychological wellbeing, and substance use during the COVID-19 pandemic: A rapid review}

Since the World Health Organization declared a health emergency in March 2020, the COVID-19 pandemic has destabilized life around the globe. The imposition of public health measures intended to protect populations against infection may additionally affect physical, mental, and emotional health as people endure extended 'stay-at-home' periods or expose themselves to infection risk outside the home. In many settings, schools and universities were not physically accessible during the pandemic; these 'lockdown' periods disrupted the daily routines, physical activities, social lives, and educational progress of many children and young people (Lee, 2020). Due to their sensitive psychosocial developmental stage, children and adolescents may be particularly vulnerable to the psychological distress resulting from these changes with the potential for long-term consequences (CDC, 2019; Magson et al., 2021; Racine et al., 2020). Indeed, children demonstrated symptoms of post-traumatic stress disorder (PTSD) in the wake of previous epidemics (Sprang \& Silman, 2013), and initial evidence suggests that the COVID-19 pandemic has been a traumatic experience for young people (Conti et al., 2020; Ruff \& Linville, 2021). As anxiety disorders and high levels of stress are associated with increased alcohol use among adults, alcohol use may become problematic for youth experiencing the disruption and social restriction characteristic of the pandemic period (Keyes et al., 2012; Paltell et al., 2020). The risk is further exacerbated by the lack some of the mechanisms of resilience and coping that develop with adulthood, thereby potentiating avoidant coping strategies such as substance use (Bartel et al., 2020; Dumas et al., 2020; Jones et al., 2021). These psychological challenges are particularly worrisome as youth mental health and substance use problems predict lifelong 
mental and physical health outcomes (Caspi et al., 2006; Hemmingsson et al., 2008; Merline et al., 2004).

Previous research on traumatic or stressful events suggests that youth with pre-existing mental health or substance use problems may be particularly vulnerable to psychological stress and negative coping strategies during the pandemic (Zijlmans et al., 2021). For example, in the aftermath of the 9/11 World Trade Center terrorist attack, New York City high school students who reported prior trauma and PTSD were more likely to increase their cigarette smoking than were other students (Wu et al., 2006). These issues may be particularly relevant in the context of school closures (Lee, 2020), as school-based support services have been shown to improve youth clinical and academic outcomes for youth with mental health problems (Kang-Yi et al., 2018; Owens et al., 2008). Pandemic-related stress may also be exacerbated among marginalized youth populations (e.g., youth who are racialized, LGBTQ2S+, housinginsecure/homeless, or maltreated), who already experience higher rates of social stress (Valentine \& Shipherd, 2018) and worse health outcomes (Jones et al., 2020), and lower rates of service utilization (Banks, 2021) compared to the general youth population. The pandemic context may engender additional barriers to care as services are physically inaccessible or insufficiently staffed (Bagley et al., 2021; Cohen \& Bosk, 2020; Jones et al., 2020).

Much of the work on youth mental health, psychological wellbeing, and substance use during the pandemic has been focused on current mental health status rather than change relative to pre-pandemic outcomes (Al Omari et al., 2020; Turner et al., 2021; Zhou et al., 2020; Zijlmans et al., 2021). Accordingly, the findings may reflect longstanding issues rather than newly emergent ones. As the assessment of change over time is essential to understand 
outcomes specific to the ongoing pandemic (Wade et al., 2020), studies of changes in mental health problems may be more useful than one-time assessments in order to understand and offset the negative impacts of this global phenomenon.

With these factors in mind, we conducted a rapid review of the impact of the COVID-19 pandemic on youth substance use and mental health, as well as the delivery of youth substance use and mental health services. Distinct from previous reviews (Imran et al., 2020; Jones et al., 2021; Nearchou et al., 2020; Nobari et al., 2021; Oliveira et al., 2020; Panda et al., 2021; Racine et al., 2020; Singh et al., 2020; Stavridou et al., 2020), we included only studies of change from pre- to peri-pandemic contexts, and also focused on youth substance use outcomes. Thus, the contribution of this review was the assessment of changes in youth mental health, psychological wellbeing, and substance use, as well as the changes or disruptions to the delivery of mental health or substance use services for young people. 


\section{METHOD}

This review is registered with PROSPERO (registration no. CRD42021254675). We opted for the streamlined approach of a rapid review given the dynamic nature of the ongoing COVID-19 pandemic. The design of the review was informed by the Selecting Approaches for Rapid Reviews (STARR) tool (Pandor et al., 2019). Reporting is in accordance with Preferred Reporting Items for Systematic Reviews and Meta-Analyses (PRISMA) statement (Page et al., 2021) (see Appendix, Table 5).

Population of interest

"Youth" was defined as anyone under 25 years of age (WHO, 2011).

\section{Outcomes}

We extracted data on substance use, mental health outcomes, and service delivery in the context of the COVID-19 pandemic. 'Mental health' included mental disorders, for example, mood and anxiety disorders, as well as sub-clinical psychological distress and well-being. 'Substance use' was inclusive of any substance, including alcohol, nicotine, cannabis, prescribed medicines, and illicit drugs. Specific outcomes were:

1. Onset, improvement, or worsening of a mental disorder or psychological distress

2. Improvement or worsening of psychological wellbeing

3. Changes in prevalence or incidence of a mental disorder or psychological distress

4. Onset or changes in frequency or amount of substance use

5. Changes in substances used or in route of administration of substances

6. Changes in prevalence or incidence of substance use or substance use disorder 
7. Changes in access to or disruption of mental health or substance use services for youth Search strategy

Searches of peer-reviewed literature regarding youth mental health, substance use, and wellbeing in the context of the COVID-19 pandemic were undertaken in PubMed and Embase in May 2021, restricted to studies published in 2020 onwards. The search strategy was designed to facilitate rapid completion while ensuring a high level of retrieval of relevant studies. The search terms are listed in the appendix.

\section{Inclusion criteria}

We included all of the empirical studies on our target outcomes, regardless of methodology. Studies had to be focused on (1) a youth population and (2) associations between any aspect of the COVID-19 pandemic and the specified outcomes. Primary publications and systematic reviews were included. Publications regarding mental health, psychological wellbeing, or substance use during the pandemic without any comparison to a pre-pandemic time point (whether assessed prospectively or cross-sectionally) were excluded.

Population studies with participants older than 25 were included if (1) age-disaggregated results for our age range of interest were reported or (2) the majority of the sample was younger than 25 , as indicated by the mean and standard deviation of participants' ages (e.g., in a sample of undergraduate students). Publications that only included youth with a specific health condition were excluded, unless the condition was a mental health problem. 
Study selection

Study selection and screening were completed using the Covidence platform. Each citation was reviewed independently by two reviewers, with disagreements over inclusion and exclusion resolved through team discussion to reach a consensus. Reference lists of the included studies were checked for additional studies for inclusion.

\section{Risk of bias assessment}

As a rapid review, we excluded a formal risk of bias assessment (Pandor et al., 2019). However, as part of the data extraction, we recorded several aspects of the study design (e.g., prospective or retrospective assessment of change) and study population (e.g., representativeness of the study sample) that may provide an indication of risk of bias.

Data extraction and synthesis

Data were extracted into a Microsoft Excel spreadsheet to record:

- Study bibliographic details: authors, year of publication, country of publication

- Study design: qualitative, quantitative, or mixed methods; the method of assessing change since the pandemic; recruitment method; prospective or retrospective recruitment

- Study population: age range and average age of participants (child/adolescent/youth); generalizability of sample

- Study outcomes of interest and findings relating to youth substance use, mental health, wellbeing, and/or service delivery during the pandemic. 
To maximize efficiency, the data from each study was extracted once with verification by another team member. Given the broad scope of this review and the heterogeneity of included publications, we used a narrative synthesis approach, with results organized by substances or symptoms measured. 


\section{RESULTS}

\section{Overview of included studies}

We identified 4,793 publications for screening $-4,790$ from the web searches, and three additional publications through hand searching of reference lists. After screening and full-text review, 156 publications were included, all of which involved primary research (Figure 1; see Appendix, Tables 1-4).

Figure 1: Study flow diagram

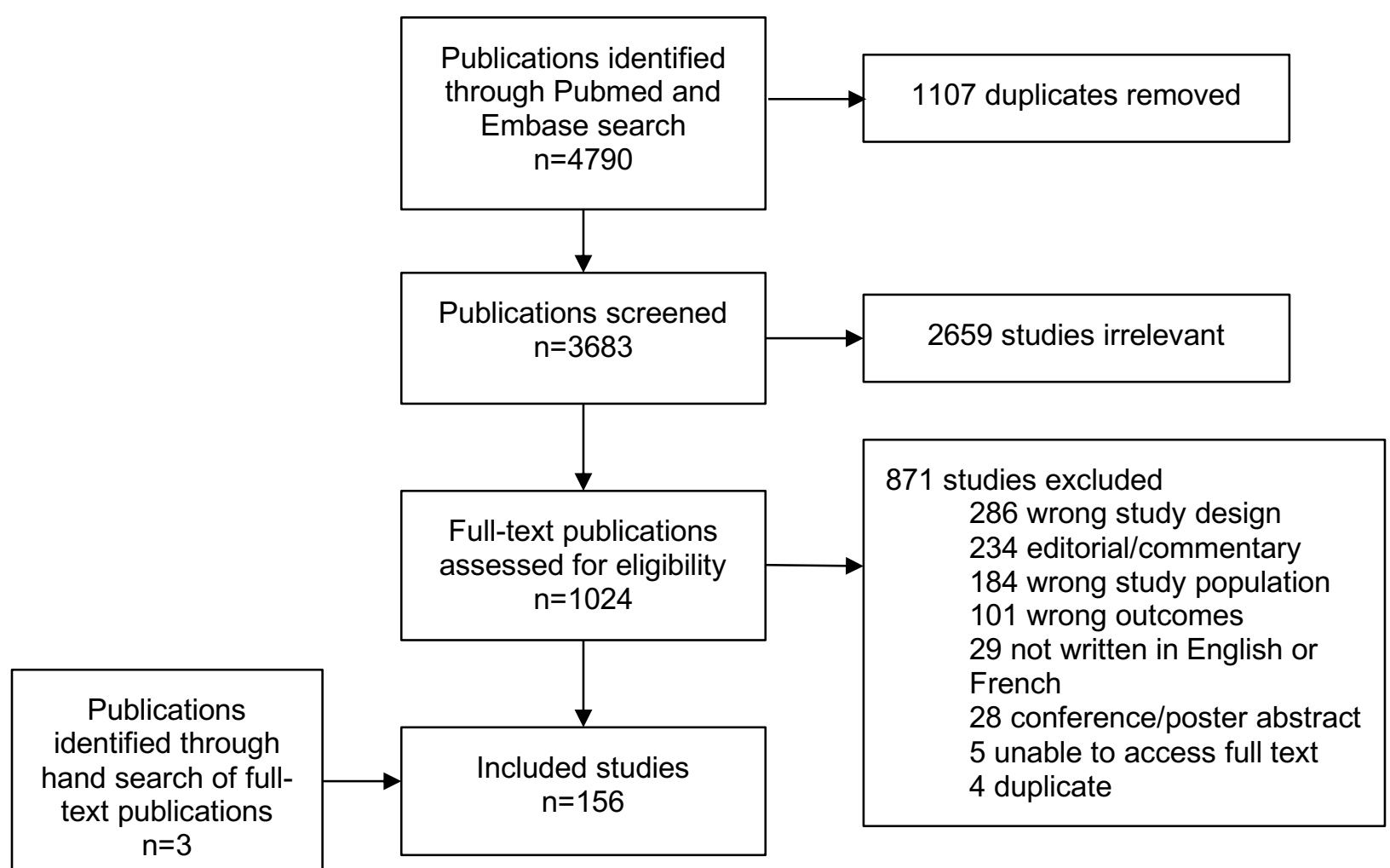




\section{Youth mental health during COVID-19}

One hundred and twenty-one publications reporting on youth mental health during the COVID19 pandemic were found (see Appendix, Table 1). Of these, 53 involved retrospective change (36 cross-sectional studies, 17 qualitative studies), 36 prospective change, and 32 included comparisons of peri-pandemic outcomes to pre-pandemic normative data. A variety of methods were used to assess changes in mental health, including measurements of pre-existing prospective cohorts, comparison to population norms, and participant self-reports. Most of the studies ( $n=112,93 \%$ ) were conducted in high-income countries, including Europe $(n=49)$, North America $(n=39)$, East Asia $(n=14)$, Southwest Asia [i.e., Israel $(n=2)$ and Saudi Arabia $(n$ $=1)$, and Australia $(n=7)$. Nine publications were conducted in lower-income countries, namely Bangladesh, India, Iraq, South Africa, Turkey, and Uganda. The participant groups varied widely, including age ranges, which included young children aged 2-5 (as reported on by their parents), school-aged children, adolescents, college and university students, and young adults. Thirty-one of the 121 publications (24\%) were conducted among student populations, whereas the other studies included clinical groups, online survey respondents, and general population surveys.

Depression or mood disorder symptoms $(n=57)$. The majority of the publications $(79 \%)$ indicated that depression or depressive symptoms worsened during the pandemic. Of the 20 longitudinal studies, 16 included reports of increased depressive symptoms during the pandemic (Bignardi et al., 2020; Breaux et al., 2021; Buckner et al., 2021; C. Y. Chen et al., 2021;

X. Chen et al., 2021; Elmer et al., 2020; Evans et al., 2021; Giuntella et al., 2021; Hawes, Szenczy, Klein, et al., 2021; Hawes, Szenczy, Olino, et al., 2021; Huckins et al., 2020; Hussong et 
al., 2021; Y. Li et al., 2021; Magson et al., 2021; Yang et al., 2021; Zhang et al., 2020), two of no significant change (Janssen et al., 2020; Teng et al., 2021), and two of fewer depressive symptoms (Li et al., 2020; Xiang et al., 2020). Participants in a qualitative study described feeling hopeless and that life was meaningless during the pandemic, as well as losing sleep and interest in activities (Suhail et al., 2020).

Anxiety or anxiety disorder symptoms $(\mathrm{n}=57)$. The majority of the publications $(76 \%)$ indicated heightened anxiety during the pandemic. Among the 21 longitudinal studies, 16 reported higher levels of anxiety (Breaux et al., 2021; C. Y. Chen et al., 2021; X. Chen et al., 2021; Conti et al., 2020; Elmer et al., 2020; Evans et al., 2021; Hawes, Szenczy, Klein, et al., 2021; Hawes, Szenczy, Olino, et al., 2021; Huckins et al., 2020; Knowles \& Olatunji, 2021; S. H. Li et al., 2021; Magson et al., 2021; Manjareeka \& Pathak, 2020; Teng et al., 2021), two indicated no significant change (Buckner et al., 2021; Zhang et al., 2020), and three reported significant decreases in anxiety scores during the lockdown (Bignardi et al., 2020; Li et al., 2020; Schwartz-Lifshitz et al., 2021). In a qualitative study, participants discussed anxiety about the social isolation and monotony of lockdown, as well as of their uncertain academic and social futures (Gittings et al., 2021).

Stress or distress $(n=32)$. Similar to the findings regarding depression and anxiety, 23 of the included publications (72\%) indicated higher levels of stress or psychological stress among youth during the pandemic. Among the nine longitudinal studies on these problems, six indicated higher levels of (dis)stress (Baliyan et al., 2021; Breaux et al., 2021; Elmer et al., 2020; Gray et al., 2020; Magson et al., 2021; Savage et al., 2020), two indicated no significant changes (Copeland et al., 2021; Munasinghe et al., 2020), and one indicated a decrease in "acute stress" (but increases in depression and anxiety symptoms as reported above) (Y. Li et al., 2021). 
Externalizing behaviors $(\mathrm{n}=24)$. Overall, 16 publications $(67 \%)$ indicated increases in externalizing behavior, six indicated no significant changes (25\%), and two indicated reductions (8\%). Of the eight longitudinal studies, two indicated an overall worsening of symptoms (Copeland et al., 2021; Hussong et al., 2021), two indicated no overall change (Bailey et al., 2021; Ezpeleta et al., 2020), and two indicated improvements in externalizing behavior (Achterberg et al., 2021; Penner et al., 2021). A longitudinal study of adolescents with and without diagnoses of Attention Deficit Hyperactivity Disorder (ADHD) in the United States indicated significant increases in inattention but no change in hyperactivity (Breaux et al., 2021). Additionally, a study of Italian children and adolescents with ADHD indicated different trends for youth with mild- or moderate-severity ADHD, whose symptoms generally improved during the pandemic, compared to those with high-severity ADHD, who demonstrated increases in most problematic behaviors (Melegari et al., 2021).

Self-harm or suicide $(\mathrm{n}=14)$. Publications from the United States, China, Australia, and Greece indicated increases in suicidal ideation during the pandemic (Batchelor et al., 2021; Hill et al., 2021; Kaparounaki et al., 2020; Raviv et al., 2021; Son et al., 2020; Zhang et al., 2020). In Japan, no significant change in the suicide rate among youth was noted during the first wave of the pandemic (Isumi et al., 2020), but the monthly suicide rate among people younger than 20 increased by $49 \%$ during the second wave (Tanaka \& Okamoto, 2021). In contrast, a study of youth detained by the criminal legal system in Australia indicated a four-fold reduction in selfharming incidents during the pandemic compared to the same period in 2019 (Kasinathan et al., 2021). 


\section{Youth wellbeing and resilience during COVID-19}

Twenty-six publications were focused on youth wellbeing, life satisfaction, quality of life, resilience, and/or coping strategies during the COVID-19 pandemic (see Appendix, Table 2). Of these, 12 were assessments of retrospective change (five cross-sectional studies, seven qualitative studies), eight of prospective change, and six of comparisons of peri-pandemic outcomes to pre-pandemic normative data. All of the studies were conducted in high-income countries, with 14 from Europe, nine from North America, two from Australia and one from South Korea. Samples generally included adolescents aged 13-18 years, although publications also included school-age children, college or university students, and vulnerable subgroups such as youth in foster care (Vallejo-Slocker et al., 2020) or sexual minority adolescents (Nelson et al., 2020; O'Brien et al., 2021).

Wellbeing, life satisfaction, or quality of life $(\mathrm{n}=20)$. Of seven longitudinal studies of youth wellbeing or life satisfaction, six indicated a significant worsening during the pandemic period (Ehrler et al., 2021; Evans et al., 2021; Gray et al., 2020; Magson et al., 2021; Mastorci et al., 2021; Savage et al., 2020). Eight of 10 cross-sectional studies also indicated lower levels of wellbeing or life satisfaction during the pandemic, while two indicated no significant changes. In a qualitative study, young people in the UK attributed their feelings of frustration, anger, and disappointment to the constant change, uncertainly, and lack of control associated with the pandemic context (Scott et al., 2021).

Resilience and coping strategies $(\mathrm{n}=7)$. Youth resilience and coping strategies during the pandemic were often reported in qualitative publications in which resilience and some positive 
coping strategies were noted among adolescents despite experiencing more negative than positive psychological impacts of school closure, adolescents demonstrated (Banks, 2021; Branquinho et al., 2020). The positive coping strategies included staying connected to others and maintaining positivity (Waselewski et al., 2020), as well as exercising, going outdoors, and engaging in creative pursuits (O'Brien et al., 2021). In a longitudinal study in the United States, youth who engaged in problem-focused coping experienced fewer mental health symptoms during the pandemic (Hussong et al., 2021).

\section{Youth substance use during COVID-19}

Forty-one publications included reports on youth substance use during the COVID-19 pandemic (see Appendix, Table 3). Of these, 26 assessed retrospective change (23 cross-sectional studies, three qualitative studies), seven measured prospective change, and eight involved comparisons between peri-pandemic outcomes and pre-pandemic normative data. Most of the studies $(n=$ $39,95 \%)$ were conducted in high-income countries, generally in North America $(n=23)$ and Europe $(n=13)$, as well as one in each of Australia, Hong Kong, and Saudi Arabia. Only two publications were from lower-income countries, namely Pakistan and Uganda. The participants were adolescents and young adults, generally ranging in age from 13 to 24 . Study populations varied, with 17 of the 41 publications (41\%) sampling secondary or higher education students; a few studies targeted the recruitment of people who use alcohol (Callinan et al., 2020) or other substances (Bonar, Chapman, et al., 2021), or focused on marginalized youth subgroups, such as unhoused (Tucker et al., 2020) or sexual and gender minority young adults (Cerezo et al., 2021). 
Alcohol $(\mathrm{n}=24)$. Fifteen publications $(63 \%)$ reported declines in alcohol use during the pandemic period, including consumption prevalence (Bourion-Bedes et al., 2021; Evans et al., 2021; Ryerson et al., 2021; Tavolacci et al., 2021; Thorisdottir et al., 2021), frequency (Bonar, Parks, et al., 2021; Szajnoga et al., 2020), and quantity (Jaffe et al., 2021; Mohler-Kuo et al., 2021; Niedzwiedz et al., 2021; Steffen et al., 2021; White et al., 2020), as well as lower average scores on the Alcohol Use Disorders Identification Test (AUDIT) (Callinan et al., 2020). Six studies (25\%) found increases in alcohol consumption (Charles et al., 2021; Coakley et al., 2021; Sharma et al., 2020; Znazen et al., 2021), including increased Emergency Department admissions for alcohol intoxication among youth in Italy (Grigoletto et al., 2020), and qualitative findings that social media drinking games normalized alcohol consumption during lockdown among university students in California, USA (Cerezo et al., 2021). A study of Canadian high school students found different behavioral changes for overall alcohol use compared to binge drinking during the lockdown period. Students who consumed alcohol reported drinking more frequently, but the overall prevalence of alcohol use remained unchanged. In contrast, binge drinking was less prevalent during the lockdown, but the students who continued to binge drink continued to do so at the same rate (Dumas et al., 2020). Three additional publications (13\%) indicated no changes in alcohol consumption measures (Bonar, Parks, et al., 2021; Chaffee et al., 2021; Husky et al., 2020).

Nicotine $(\mathrm{n}=17)$. Fourteen publications $(82 \%)$ revealed either overall declines (Dumas et al., 2020; Gaiha et al., 2020; Kreslake et al., 2021; Niedzwiedz et al., 2021; Sharma et al., 2020; Sokolovsky et al., 2021; Tavolacci et al., 2021; Thorisdottir et al., 2021; Tucker et al., 2020) or no change in the prevalence and frequency of nicotine consumption among youth during the 
pandemic period (Bonar, Chapman, et al., 2021; Bourion-Bedes et al., 2021; Chaffee et al., 2021; Hopkins \& Al-Hamdani, 2020; Matovu et al., 2021). Nearly half of American young adults participating in a longitudinal study reported reducing their e-cigarette use during the pandemic, although about a quarter of the respondents reported increasing their use (Kreslake et al., 2021). The overall prevalence of tobacco smoking was found to increase in only two publications (12\%), both of which involved university students (Ahmed et al., 2020; Znazen et al., 2021). The pattern of overall decline or stability held true for all nicotine consumption products, including e-cigarettes and vapes.

Cannabis $(\mathrm{n}=10)$. Three publications indicated overall declines (Palamar et al., 2021; Tavolacci et al., 2021; Tucker et al., 2020) and two indicted no significant overall change (Chaffee et al., 2021; Liébana-Presa et al., 2020) in the prevalence or frequency of cannabis consumption among youth during the pandemic period, with only one study indicating increased cannabis consumption frequency among the majority of its participants (Bonar, Chapman, et al., 2021). However, the findings were mixed within studies with roughly equal proportions of young adults in the Midwestern US reported increasing and decreasing their cannabis consumption during the pandemic (Sharma et al., 2020). Similarly, in a study of Canadian high school students the prevalence of cannabis use decreased during the pandemic period; although the youth who continued to use cannabis reported doing so more frequently (Dumas et al., 2020).

Other drugs or "substance use" unspecified $(\mathrm{n}=9)$ ). Seven publications were focused on changes in "substance use" across substances. While university students in the southeastern United States reported no significant changes to their use of substances other than alcohol (Charles et al., 2021), increases in both the number of substances used and the frequency of use were 
found in a longitudinal study of high school students in the United States (Cho et al., 2021) . In qualitative studies in both the United States and Portugal, adolescents reported using alcohol or "other drugs" as a form of escapism during lockdown (Branquinho et al., 2020; O'Brien et al., 2021).

Only two publications specifically were focused on substances other than alcohol, nicotine, and cannabis. Partygoers in New York City tended to reduce their use of cocaine, ecstasy, and LSD during COVID-related social distancing (Palamar et al., 2021). In contrast, in the state of Ohio, overdose deaths among people aged 24 years and younger in May 2020 were 2.06 times the May 2018-2019 mean (42 vs 20 deaths) (Currie et al., 2021). Most of these overdoses involved opioids, the use of which was not reported in the other publications.

\section{Delivery of youth substance use or mental health services during COVID-19}

Eleven publications were focused on service use or delivery for youth during the COVID-19 pandemic, including five on change retrospectively (three cross-sectional and two qualitative studies) and six on a comparison of service use data the pandemic to pre-pandemic norms (see Appendix, Table 4). All 11 publications were conducted in high-income countries, including the United States $(n=6)$, Australia $(n=2)$, and one each from Canada, France, and Hong Kong. The participants in these studies were often those seeking or receiving services, including primary mental health care (Nicholas et al., 2021), emergency psychiatric services (Ferrando et al., 2021; Leeb et al., 2020), and smoking cessation support (Ho et al., 2020). Many studies were focused on youth with pre-existing mental health conditions (Hawke et al., 2020; Ligus et al., 2021), such as ADHD (Becker et al., 2020; Bobo et al., 2020), and were generally conducted among 
adolescent or young adult populations, though two included younger children (Batchelor et al., 2021; Bobo et al., 2020).

Substance use service demand and access. Two publications were on substance use services. A study of youth accessing a smoking cessation phone line in Hong Kong indicated an increase in call volume during the pandemic, with $43 \%$ of callers agreeing that the pandemic had motivated their intention to quit, and $83 \%$ reporting a change in their smoking habits during the pandemic (Ho et al., 2020). In a cross-sectional study of Canadian youth, $5 \%$ of the sample reported needing substance use services but not receiving them during the pandemic period (Hawke et al., 2020).

Mental health service access. Some youth reported difficulty maintaining access to mental health counseling or supportive therapies (Becker et al., 2020; Ligus et al., 2021). However, for clinical services that were able to transition, telehealth was generally positively received by youth and their caregivers despite difficulties with internet connectivity and other technical issues (Bobo et al., 2020; Nicholas et al., 2021). These technological barriers to access are more likely to affect disadvantaged youth, as was reported by Black adolescents in North Carolina (Banks, 2021).

Mental health service demand. Demand for mental healthcare showed mixed effects of the pandemic. In Melbourne, Australia, overall use of primary mental health services decreased, but among those who accessed services, rates of attendance increased (Nicholas et al., 2021). Additionally, the Australian Kids Helpline received more online contacts than in previous years, many of which were related to mental health concerns (Batchelor et al., 2021). In the United States, overall volume of children's mental health-related emergency department visits 
decreased (Ferrando et al., 2021; Leeb et al., 2020), but the proportion of emergency department visits for mental health-related concerns increased beginning in late-March to October 2020 relative to the same period in 2019 (Leeb et al., 2020). 


\section{DISCUSSION}

We systematically reviewed the literature to understand changes in youth mental health, psychological wellbeing, and substance use during the COVID-19 pandemic. In contrast to previous pandemic-era reviews, this is the first review to be specifically focused on changes in these outcomes during the pandemic. The body of evidence included in this review indicates the potential for serious mental health problems among youth during the pandemic. However, findings varied both within and between mental health problem categories. While most longitudinal studies of depression symptoms, anxiety symptoms, and stress indicated increases during the pandemic, no change and even decreases in these issues were also noted. Increases in suicidal ideation and attempts in various countries were reported. However, in one of the few studies of a marginalized youth subgroup, a significant reduction in self-harming incidents during the pandemic was reported (Kasinathan et al., 2021). In most cases, youth reported decreased wellbeing and life satisfaction during the pandemic, although some studies found no significant changes. Some of these declines may have been buffered by youth resilience and the employment of positive coping strategies.

The findings regarding substance use were mixed. The impact of the pandemic on substance use has likely been moderated by a variety of factors, including changes to the social context in which people normally use substances. In-person social interaction has been dramatically reduced in many settings; for college and university student groups, a reduction in peer interaction tended to reduce alcohol use (White et al., 2020). However, social isolation may also serve to increase the use of other substances. In a longitudinal study in Canada, the 
youth who were self-isolating used more cannabis during the lockdown than did those who continued to socialize in person (Bartel et al., 2020).

Substance use and mental health problems may be exacerbated for youth who are already vulnerable due to social inequities (Jones et al., 2020; Usher et al., 2020). In the United States, racial/ethnic and sexual minorities reported experiencing disproportionately worse mental health outcomes and elevated suicidal ideation during the pandemic (Czeisler et al., 2020; Czeisler et al., 2021). The pandemic has made internet connectivity essential not only for youth social connection, but also to access information and health services, many of which have transitioned to telehealth models. A mostly positive reception for telehealth was noted, and at least one youth helpline service reported an increase in the use of its web-based services (Batchelor et al., 2021). However, telehealth and digital service access requires a reliable internet connection and the appropriate devices and spaces to facilitate a virtual appointment (Bagley et al., 2021; Walker et al., 2021). Services may also consider lower thresholds for inperson communication for vulnerable youth for whom telehealth access is limited (Jones et al., 2020). Ultimately, government action is necessary to expand telecommunications networks and increase spending on health services in order to support social connections and telehealth access for vulnerable youth.

Monitoring risk among marginalized youth

The COVID-19 pandemic has disproportionately affected marginalized peoples (Blake et al., 2021), yet many of these populations remained 'invisible' in our findings. Our initial interest was in reviewing publications regarding Indigenous youth. This interest was stymied, however, when searches resulted in only two relevant publications, neither of which included primary 
research (Jones et al., 2020; Walker et al., 2021). Similarly, the use of substances other than alcohol, nicotine, and cannabis were assessed in very few publications. When other substances were included, the proportion of participants reporting use was generally too small to analyze meaningfully. Nonetheless, opioid-related overdose deaths in the state of Ohio doubled in May 2020 as compared to previous years (Currie et al., 2021). This disconnect speaks to the necessity of research focused on vulnerable subpopulations of youth, including Indigenous youth and youth who use illicit drugs. Longitudinal research that follows members of these groups would be particularly useful in order to note changes in drug use risk before risk becomes fatality.

\section{Limitations}

\section{Limitations of the literature}

The sudden onset of the COVID-19 pandemic necessitated the rapid production of research to assess and address outcomes, yielding a body of work that is often retrospective and lacking clear pre-pandemic comparators. Change during the pandemic context is difficult to assess with studies of prevalence collected at a single time point. Some researchers attempted to address this issue by comparing measurements collected during the pandemic period to pre-pandemic norms, but sometimes these norms referred to populations that were distinctly different from their participant sample, limiting the utility of the comparison. However, longitudinal cohorts were able to provide valuable information regarding mental health, psychological wellbeing, and substance use changes during the pandemic period (e.g., Thorisdottir et al., 2021). 
In some population studies, the findings for young people could not be separated from the larger adult population. Additionally, we noted a lack of longitudinal studies on substance use among youth, and a lack of data regarding marginalized youth subpopulations.

\section{Limitations of the review}

One limitation of the review was that we did not conduct an assessment of study quality. As we extracted data on study design, we highlighted that many of the studies were based on relatively weak designs that limit the robustness of conclusions regarding change in our outcomes of interest. A second potential limitation was that we excluded publications in languages other than English or French. However, in meta-epidemiological study of clinical reviews, (Nussbaumer-Streit et al., 2020) found that the exclusion of non-English publications tends not to effect overall review conclusions, suggesting that this could be an acceptable strategy for rapid reviews.

\section{Conclusion}

In this rapid review, we highlight serious negative impacts of the COVID-19 pandemic on young people's mental health and psychological wellbeing in many settings. Findings regarding substance use were more mixed and largely limited to legal substances, warranting continued research. Further research is also necessary to elucidate pandemic impacts on vulnerable subpopulations of youth, including youth who use illicit drugs and Indigenous youth. Services will need to continue to adapt and innovate in order to support youth wellbeing in the context of a health crisis. 


\section{Acknowledgements}

Study funding: This work was supported by the Canadian Institutes of Health Research grants \#174964 and \#155942. SL is supported by a research scholar award from Fonds de recherche du Québec - Santé (296569).

\section{Contributorships:}

Conception and design: Dennis C. Wendt, Emiliana Bomfim, Jacob A. Burack, Roisin M.

O’Connor, Sarah Larney

Data collection: Camille Zolopa, Emiliana Bomfim, Charlotte Corran, Sarah DeGrace, Julianna

Dumont, Jessica Lai

Analysis and interpretation of results: Camille Zolopa, Sarah Larney, Dennis C. Wendt, Jacob A. Burack, Roisin M. O’Connor, Charlotte Corran, Jessica Lai

Manuscript preparation: Camille Zolopa, Sarah Larney, Jacob A. Burack, Roisin M. O’Connor, Charlotte Corran, Jessica Lai, Dennis C. Wendt

Conflicts of interest: The authors have declared that they have no competing or potential conflicts of interest. 


\section{References}

Achterberg, M., Dobbelaar, S., Boer, O. D., \& Crone, E. A. (2021). Perceived stress as mediator for longitudinal effects of the COVID-19 lockdown on wellbeing of parents and children. Scientific reports, 11(1), 2971. https://doi.org/http://dx.doi.org/10.1038/s41598-02181720-8

Ahmed, M., Hamid, R., Hussain, G., Bux, M., Ahmed, N., \& Kumar, M. (2020). Anxiety and depression in medical students of Sindh province during the covid-19 pandemic. Rawal Medical Journal, 45(4), 947-950. https://www.rmj.org.pk/index.php?fulltxt=123902\&fulltxtj=27\&fulltxtp=271597076831.pdf

Al Omari, O., Al Sabei, S., Al Rawajfah, O., Abu Sharour, L., Aljohani, K., Alomari, K., Shkman, L., Al Dameery, K., Saifan, A., Al Zubidi, B., Anwar, S., \& Alhalaiqa, F. (2020). Prevalence and Predictors of Depression, Anxiety, and Stress among Youth at the Time of COVID-19: An Online Cross-Sectional Multicountry Study. Depress Res Treat, 2020, 8887727. https://doi.org/10.1155/2020/8887727

Bagley, S. M., Hadland, S. E., \& Yule, A. M. (2021). A commentary on the impact of COVID19 on engagement of youth with substance use and co-occurring psychiatric disorders. Journal of substance abuse treatment, 121, 108175. https://www.ncbi.nlm.nih.gov/pmc/articles/PMC7575435/pdf/main.pdf

Bailey, T., Hastings, R. P., \& Totsika, V. (2021). COVID-19 impact on psychological outcomes of parents, siblings and children with intellectual disability: longitudinal before and during lockdown design. Journal of Intellectual Disability Research, 65(5), 397-404. https://doi.org/http://dx.doi.org/10.1111/jir.12818

Baliyan, S., Cimadevilla, J. M., de Vidania, S., Pulopulos, M. M., Sandi, C., \& Venero, C. (2021). Differential susceptibility to the impact of the COVID-19 pandemic on working memory, empathy, and perceived stress: The role of cortisol and resilience. Brain Sciences, 11(3). https://doi.org/http://dx.doi.org/10.3390/brainsci11030348

Banks, A. (2021). Black Adolescent Experiences with COVID-19 and Mental Health Services Utilization. Journal of racial and ethnic health disparities., 28. https://doi.org/http://dx.doi.org/10.1007/s40615-021-01049-w

Bartel, S. J., Sherry, S. B., \& Stewart, S. H. (2020). Self-isolation: A significant contributor to cannabis use during the COVID-19 pandemic. Substance abuse, 41(4), 409-412. https://doi.org/http://dx.doi.org/10.1080/08897077.2020.1823550 
Batchelor, S., Stoyanov, S., Pirkis, J., \& Kolves, K. (2021). Use of Kids Helpline by Children and Young People in Australia During the COVID-19 Pandemic. Journal of Adolescent Health. https://doi.org/http://dx.doi.org/10.1016/j.jadohealth.2021.03.015

Becker, S. P., Breaux, R., Cusick, C. N., Dvorsky, M. R., Marsh, N. P., Sciberras, E., \& Langberg, J. M. (2020). Remote Learning During COVID-19: Examining School Practices, Service Continuation, and Difficulties for Adolescents With and Without Attention-Deficit/Hyperactivity Disorder. Journal of Adolescent Health, 67(6), 769-777. https://doi.org/http://dx.doi.org/10.1016/j.jadohealth.2020.09.002

Bignardi, G., Dalmaijer, E. S., Anwyl-Irvine, A. L., Smith, T. A., Siugzdaite, R., Uh, S., \& Astle, D. E. (2020). Longitudinal increases in childhood depression symptoms during the COVID-19 lockdown. Archives of Disease in Childhood, (no pagination). https://doi.org/http://dx.doi.org/10.1136/archdischild-2020-320372

Blake, H., Brown, N., Follette, C., Morgan, J., \& Yu, H. (2021). Black, Indigenous, People of Color, and International Students: Experiences and Resolutions Beyond COVID-19. American journal of public health, 111(3), 384-386.

Bobo, E., Lin, L., Acquaviva, E., Caci, H., Franc, N., Gamon, L., Picot, M. C., Pupier, F., Speranza, M., Falissard, B., \& Purper-Ouakil, D. (2020). How do children and adolescents with Attention Deficit Hyperactivity Disorder (ADHD) experience lockdown during the COVID-19 outbreak? Encephale, 46(3 Supplement), S85-S92. https://doi.org/http://dx.doi.org/10.1016/j.encep.2020.05.011

Bonar, E. E., Chapman, L., McAfee, J., Goldstick, J. E., Bauermeister, J. A., Carter, P. M., Young, S. D., \& Walton, M. A. (2021). Perceived impacts of the COVID-19 pandemic on cannabis-using emerging adults. Transl Behav Med. https://doi.org/10.1093/tbm/ibab025

Bonar, E. E., Parks, M. J., Gunlicks-Stoessel, M., Lyden, G. R., Mehus, C. J., Morrell, N., \& Patrick, M. E. (2021). Binge drinking before and after a COVID-19 campus closure among first-year college students. Addictive Behaviors, 118 (no pagination). https://doi.org/http://dx.doi.org/10.1016/j.addbeh.2021.106879

Bourion-Bedes, S., Tarquinio, C., Batt, M., Tarquinio, P., Lebreuilly, R., Sorsana, C., Legrand, K., Rousseau, H., \& Baumann, C. (2021). Stress and associated factors among French university students under the COVID-19 lockdown: The results of the PIMS-CoV 19 study. Journal of Affective Disorders, 283, 108-114. https://doi.org/http://dx.doi.org/10.1016/j.jad.2021.01.041

Branquinho, C., Kelly, C., Arevalo, L. C., Santos, A., \& Gaspar de Matos, M. (2020). "Hey, we also have something to say": A qualitative study of Portuguese adolescents' and young 
people's experiences under COVID-19. Journal of community psychology, 48(8), 27402752. https://doi.org/http://dx.doi.org/10.1002/jcop.22453

Breaux, R., Dvorsky, M. R., Marsh, N. P., Green, C. D., Cash, A. R., Shroff, D. M., Buchen, N., Langberg, J. M., \& Becker, S. P. (2021). Prospective impact of COVID-19 on mental health functioning in adolescents with and without ADHD: protective role of emotion regulation abilities. Journal of child psychology and psychiatry, and allied disciplines., 04. https://doi.org/http://dx.doi.org/10.1111/jcpp.13382

Buckner, J. D., Abarno, C. N., Lewis, E. M., Zvolensky, M. J., \& Garey, L. (2021). Increases in distress during stay-at-home mandates During the COVID-19 pandemic: A longitudinal study. Psychiatry Research, 298 (no pagination). https://doi.org/http://dx.doi.org/10.1016/j.psychres.2021.113821

Callinan, S., Smit, K., Mojica-Perez, Y., D'Aquino, S., Moore, D., \& Kuntsche, E. (2020). Shifts in alcohol consumption during the COVID-19 pandemic: early indications from Australia. Addiction, 02. https://doi.org/http://dx.doi.org/10.1111/add.15275

Caspi, A., Harrington, H., Moffitt, T. E., Milne, B. J., \& Poulton, R. (2006). Socially Isolated Children 20 Years Later: Risk of Cardiovascular Disease. Archives of Pediatrics \& Adolescent Medicine, 160(8), 805-811. https://doi.org/10.1001/archpedi.160.8.805

CDC. (2019). How are Children Different from Adults. https://www.cdc.gov/childrenindisasters/differences.html

Cerezo, A., Ramirez, A., O'Shaughnessy, T., Sanchez, A., Mattis, S., \& Ross, A. (2021). Understanding the Power of Social Media during COVID-19: Forming Social Norms for Drinking among Sexual Minority Gender Expansive College Women. Journal of homosexuality, 68(4), 560-576. https://doi.org/http://dx.doi.org/10.1080/00918369.2020.1868183

Chaffee, B. W., Cheng, J., Couch, E. T., Hoeft, K. S., \& Halpern-Felsher, B. (2021). Adolescents' Substance Use and Physical Activity before and during the COVID-19 Pandemic. JAMA Pediatrics, E1-E8. https://doi.org/http://dx.doi.org/10.1001/jamapediatrics.2021.0541

Charles, N. E., Strong, S. J., Burns, L. C., Bullerjahn, M. R., \& Serafine, K. M. (2021). Increased mood disorder symptoms, perceived stress, and alcohol use among college students during the COVID-19 pandemic. Psychiatry Research, 296 (no pagination). https://doi.org/http://dx.doi.org/10.1016/j.psychres.2021.113706 
Chen, C. Y., Chen, I. H., Hou, W. L., Potenza, M. N., O'Brien, K. S., Lin, C. Y., \& Latner, J. D. (2021). The Relationship Between Children's Problematic Internet-related Behaviors and Psychological Distress During the Onset of the COVID-19 Pandemic: A Longitudinal Study. J Addict Med. https://doi.org/10.1097/adm.0000000000000845

Chen, X., Qi, H., Liu, R., Feng, Y., Li, W., Xiang, M., Cheung, T., Jackson, T., Wang, G., \& Xiang, Y. T. (2021). Depression, anxiety and associated factors among Chinese adolescents during the COVID-19 outbreak: a comparison of two cross-sectional studies. Translational Psychiatry, 11(1). https://doi.org/http://dx.doi.org/10.1038/s41398-021$\underline{01271-4}$

Cho, J., Bello, M. S., Christie, N. C., Monterosso, J. R., \& Leventhal, A. M. (2021). Adolescent emotional disorder symptoms and transdiagnostic vulnerabilities as predictors of young adult substance use during the COVID-19 pandemic: mediation by substance-related coping behaviors. Cognitive behaviour therapy, 1-19. https://doi.org/http://dx.doi.org/10.1080/16506073.2021.1882552

Coakley, K. E., Lardier, D. T., Holladay, K. R., Amorim, F. T., Mechler, H., \& Zuhl, M. N. (2021). Mental Health Severity Is Associated with Increases in Alcohol Consumption in Young Adult Students during the COVID-19 Pandemic. Alcoholism Treatment Quarterly. https://doi.org/http://dx.doi.org/10.1080/07347324.2021.1917325

Cohen, R. I. S., \& Bosk, E. A. (2020). Vulnerable youth and the COVID-19 pandemic. Pediatrics, 146(1).

Conti, E., Sgandurra, G., De Nicola, G., Biagioni, T., Boldrini, S., Bonaventura, E., Buchignani, B., Vecchia, S. D., Falcone, F., Fedi, C., Gazzillo, M., Marinella, G., Mazzullo, C., Micomonaco, J., Pantalone, G., Salvati, A., Sesso, G., Simonelli, V., Tolomei, G., Troiano, I., Cioni, G., Masi, G., Muratori, F., Milone, A., \& Battini, R. (2020). Behavioural and emotional changes during covid-19 lockdown in an italian paediatric population with neurologic and psychiatric disorders. Brain Sciences, 10(12), 1-15. https://doi.org/http://dx.doi.org/10.3390/brainsci10120918

Copeland, W. E., McGinnis, E., Bai, Y., Adams, Z., Nardone, H., Devadanam, V., Rettew, J., \& Hudziak, J. J. (2021). Impact of COVID-19 Pandemic on College Student Mental Health and Wellness. Journal of the American Academy of Child and Adolescent Psychiatry, 60(1), 134-141.e132. https://doi.org/http://dx.doi.org/10.1016/j.jaac.2020.08.466

Currie, J. M., Schnell, M. K., Schwandt, H., \& Zhang, J. (2021). Trends in Drug Overdose Mortality in Ohio during the First 7 Months of the COVID-19 Pandemic. JAMA Network Open, 4(4). https://doi.org/http://dx.doi.org/10.1001/jamanetworkopen.2021.7112 
Czeisler, M. E., Lane, R. I., Petrosky, E., Wiley, J. F., Christensen, A., Njai, R., Weaver, M. D., Robbins, R., Facer-Childs, E. R., Barger, L. K., Czeisler, C. A., Howard, M. E., \& Rajaratnam, S. M. W. (2020). Mental Health, Substance Use, and Suicidal Ideation During the COVID-19 Pandemic - United States, June 24-30, 2020. Mmwr, Morbidity and mortality weekly report. 69(32), 1049-1057. https://doi.org/http://dx.doi.org/10.15585/mmwr.mm6932a1

Czeisler, M. E., Lane, R. I., Wiley, J. F., Czeisler, C. A., Howard, M. E., \& Rajaratnam, S. M. W. (2021). Follow-up Survey of US Adult Reports of Mental Health, Substance Use, and Suicidal Ideation during the COVID-19 Pandemic, September 2020. JAMA Network Open, 4(2). https://doi.org/http://dx.doi.org/10.1001/jamanetworkopen.2020.37665

Dumas, T. M., Ellis, W., \& Litt, D. M. (2020). What Does Adolescent Substance Use Look Like During the COVID-19 Pandemic? Examining Changes in Frequency, Social Contexts, and Pandemic-Related Predictors. Journal of Adolescent Health, 67(3), 354-361. https://doi.org/http://dx.doi.org/10.1016/j.jadohealth.2020.06.018

Ehrler, M., Werninger, I., Schnider, B., Eichelberger, D. A., Naef, N., Disselhoff, V., Kretschmar, O., Hagmann, C. F., Latal, B., \& Wehrle, F. M. (2021). Impact of the COVID-19 pandemic on children with and without risk for neurodevelopmental impairments. Acta Paediatrica, International Journal of Paediatrics, 110(4), 1281-1288. https://doi.org/http://dx.doi.org/10.1111/apa.15775

Elmer, T., Mepham, K., \& Stadtfeld, C. (2020). Students under lockdown: Comparisons of students' social networks and mental health before and during the COVID-19 crisis in Switzerland. PLoS ONE, 15(7), e0236337. https://doi.org/10.1371/journal.pone.0236337

Evans, S., Alkan, E., Bhangoo, J. K., Tenenbaum, H., \& Ng-Knight, T. (2021). Effects of the COVID-19 lockdown on mental health, wellbeing, sleep, and alcohol use in a UK student sample. Psychiatry Research, 298 (no pagination). https://doi.org/http://dx.doi.org/10.1016/j.psychres.2021.113819

Ezpeleta, L., Navarro, J. B., de la Osa, N., Trepat, E., \& Penelo, E. (2020). Life conditions during COVID-19 lockdown and mental health in Spanish adolescents. International Journal of Environmental Research and Public Health, 17(19), 1-13. https://doi.org/http://dx.doi.org/10.3390/ijerph17197327

Ferrando, S. J., Klepacz, L., Lynch, S., Shahar, S., Dornbush, R., Smiley, A., Miller, I., Tavakkoli, M., Regan, J., \& Bartell, A. (2021). Psychiatric emergencies during the height of the COVID-19 pandemic in the suburban New York City area. Journal of Psychiatric Research, 136, 552-559. https://doi.org/http://dx.doi.org/10.1016/j.jpsychires.2020.10.029 
Gaiha, S. M., Lempert, L. K., \& Halpern-Felsher, B. (2020). Underage youth and young adult ecigarette use and access before and during the coronavirus disease 2019 pandemic. JAMA Network Open, 3(12). https://doi.org/http://dx.doi.org/10.1001/jamanetworkopen.2020.27572

Gittings, L., Toska, E., Medley, S., Cluver, L., Logie, C. H., Ralayo, N., Chen, J., \& MbithiDikgole, J. (2021). 'Now my life is stuck!': Experiences of adolescents and young people during COVID-19 lockdown in South Africa. Global Public Health. https://doi.org/http://dx.doi.org/10.1080/17441692.2021.1899262

Giuntella, O., Hyde, K., Saccardo, S., \& Sadoff, S. (2021). Lifestyle and mental health disruptions during COVID-19. Proceedings of the National Academy of Sciences of the United States of America, 118(9). https://doi.org/http://dx.doi.org/10.1073/pnas.2016632118

Gray, N. S., O'Connor, C., Knowles, J., Pink, J., Simkiss, N. J., Williams, S. D., \& Snowden, R. J. (2020). The Influence of the COVID-19 Pandemic on Mental Well-Being and Psychological Distress: Impact Upon a Single Country. Frontiers in Psychiatry, 11 (no pagination). https://doi.org/http://dx.doi.org/10.3389/fpsyt.2020.594115

Grigoletto, V., Cognigni, M., Occhipinti, A. A., Abbracciavento, G., Carrozzi, M., Barbi, E., \& Cozzi, G. (2020). Rebound of Severe Alcoholic Intoxications in Adolescents and Young Adults After COVID-19 Lockdown. Journal of Adolescent Health, 67(5), 727-729. https://doi.org/http://dx.doi.org/10.1016/j.jadohealth.2020.08.017

Hawes, M. T., Szenczy, A. K., Klein, D. N., Hajcak, G., \& Nelson, B. D. (2021). Increases in Depression and Anxiety Symptoms in Adolescents and Young Adults during the COVID-19 Pandemic. Psychological medicine, 1-25. https://doi.org/http://dx.doi.org/10.1017/S0033291720005358

Hawes, M. T., Szenczy, A. K., Olino, T. M., Nelson, B. D., \& Klein, D. N. (2021). Trajectories of depression, anxiety and pandemic experiences; A longitudinal study of youth in New York during the Spring-Summer of 2020. Psychiatry Research, 298 (no pagination). https://doi.org/http://dx.doi.org/10.1016/j.psychres.2021.113778

Hawke, L. D., Barbic, S. P., Voineskos, A., Szatmari, P., Cleverley, K., Hayes, E., Relihan, J., Daley, M., Courtney, D., Cheung, A., Darnay, K., \& Henderson, J. L. (2020). Impacts of COVID-19 on Youth Mental Health, Substance Use, and Well-being: A Rapid Survey of Clinical and Community Samples: Repercussions de la COVID-19 sur la sante mentale, l'utilisation de substances et le bien-etre des adolescents : un sondage rapide 
d'echantillons cliniques et communautaires. Canadian Journal of Psychiatry, 65(10), 701-709. https://doi.org/http://dx.doi.org/10.1177/0706743720940562

Hemmingsson, T., Kriebel, D., Tynelius, P., Rasmussen, F., \& Lundberg, I. (2008, Feb). Adolescent mental health predicts quitting smoking in adulthood: a longitudinal analysis. Eur J Public Health, 18(1), 66-70. https://doi.org/10.1093/eurpub/ckm079

Hill, R. M., Rufino, K., Kurian, S., Saxena, J., Saxena, K., \& Williams, L. (2021). Suicide ideation and attempts in a pediatric emergency department before and during COVID-19. Pediatrics, 147(3). https://doi.org/http://dx.doi.org/10.1542/PEDS.2020-029280

Ho, L. L. K., Li, W. H. C., Cheung, A. T., Xia, W., Wang, M. P., Cheung, D. Y. T., \& Lam, T. H. (2020). Impact of COVID-19 on the hong kong youth quitline service and quitting behaviors of its users. International Journal of Environmental Research and Public Health, 17(22), 1-8. https://doi.org/http://dx.doi.org/10.3390/ijerph17228397

Hopkins, D. B., \& Al-Hamdani, M. (2020). Young Canadian e-Cigarette Users and the COVID19 Pandemic: Examining Vaping Behaviors by Pandemic Onset and Gender. Frontiers in public health, 8, 620748. https://doi.org/http://dx.doi.org/10.3389/fpubh.2020.620748

Huckins, J. F., da Silva, A. W., Wang, W., Hedlund, E., Rogers, C., Nepal, S. K., Wu, J., Obuchi, M., Murphy, E. I., Meyer, M. L., Wagner, D. D., Holtzheimer, P. E., \& Campbell, A. T. (2020). Mental health and behavior of college students during the early phases of the COVID-19 pandemic: Longitudinal smartphone and ecological momentary assessment study. Journal of Medical Internet Research, 22(6). https://doi.org/http://dx.doi.org/10.2196/20185

Husky, M. M., Kovess-Masfety, V., \& Swendsen, J. D. (2020). Stress and anxiety among university students in France during Covid-19 mandatory confinement. Comprehensive Psychiatry, 102 (no pagination). https://doi.org/http://dx.doi.org/10.1016/j.comppsych.2020.152191

Hussong, A. M., Midgette, A. J., Thomas, T. E., Coffman, J. L., \& Cho, S. (2021). Coping and Mental Health in Early Adolescence during COVID-19. Research on child and adolescent psychopathology., 15. https://doi.org/http://dx.doi.org/10.1007/s10802-021$\underline{00821-0}$

Imran, N., Aamer, I., Sharif, M. I., Bodla, Z. H., \& Naveed, S. (2020). Psychological burden of quarantine in children and adolescents: A rapid systematic review and proposed solutions. Pakistan Journal of Medical Sciences, 36(5), 1106-1116. https://doi.org/http://dx.doi.org/10.12669/pjms.36.5.3088 
Isumi, A., Doi, S., Yamaoka, Y., Takahashi, K., \& Fujiwara, T. (2020). Do suicide rates in children and adolescents change during school closure in Japan? The acute effect of the first wave of COVID-19 pandemic on child and adolescent mental health. Child Abuse and Neglect, Part 2. 110 (no pagination). https://doi.org/http://dx.doi.org/10.1016/j.chiabu.2020.104680

Jaffe, A. E., Kumar, S. A., Ramirez, J. J., \& DiLillo, D. (2021). Is the COVID-19 Pandemic a High-Risk Period for College Student Alcohol Use? A Comparison of Three Spring Semesters. Alcoholism: Clinical and Experimental Research, 45(4), 854-863. https://doi.org/http://dx.doi.org/10.1111/acer.14572

Janssen, L. H. C., Kullberg, M. L. J., Verkuil, B., van Zwieten, N., Wever, M. C. M., van Houtum, L. A. E. M., Wentholt, W. G. M., \& Elzinga, B. M. (2020). Does the COVID-19 pandemic impact parents' and adolescents' well-being? An EMA-study on daily affect and parenting. PLOS ONE, 15(10 October). https://doi.org/http://dx.doi.org/10.1371/journal.pone.0240962

Jones, B., Woolfenden, S., Pengilly, S., Breen, C., Cohn, R., Biviano, L., Johns, A., Worth, A., Lamb, R., Lingam, R., Silove, N., Marks, S., Tzioumi, D., \& Zwi, K. (2020). COVID-19 pandemic: The impact on vulnerable children and young people in Australia. Journal of Paediatrics and Child Health, 56(12), 1851-1855. https://doi.org/http://dx.doi.org/10.1111/jpc.15169

Jones, E. A. K., Mitra, A. K., \& Bhuiyan, A. R. (2021). Impact of covid-19 on mental health in adolescents: A systematic review. International Journal of Environmental Research and Public Health, 18(5), 1-9. https://doi.org/http://dx.doi.org/10.3390/ijerph18052470

Kang-Yi, C. D., Wolk, C. B., Locke, J., Beidas, R. S., Lareef, I., Pisciella, A. E., Lim, S., Evans, A. C., \& Mandell, D. S. (2018, Apr). Impact of school-based and out-of-school mental health services on reducing school absence and school suspension among children with psychiatric disorders. Eval Program Plann, 67, 105-112. https://doi.org/10.1016/j.evalprogplan.2017.12.006

Kaparounaki, C. K., Patsali, M. E., Mousa, D. P. V., Papadopoulou, E. V. K., Papadopoulou, K. K. K., \& Fountoulakis, K. N. (2020). University students' mental health amidst the COVID-19 quarantine in Greece. Psychiatry Research, 290 (no pagination). https://doi.org/http://dx.doi.org/10.1016/j.psychres.2020.113111

Kasinathan, J., Haysom, L., Andriotis, H., Wheaton, M., Lloyd, T., Langstaff, R., McClelland, R., Whiting, N., Southgate, S., Vita, M., McGrath, C., Palmai, M., Armstrong, C., O'Donovan, C., Oyan, M., Woodward, J., \& Wilson, C. (2021). Keeping COVID out: a 
collaborative approach to COVID-19 is associated with a significant reduction in selfharm in young people in custody. Australasian Psychiatry.

https://doi.org/http://dx.doi.org/10.1177/10398562211006125

Keyes, K. M., Hatzenbuehler, M. L., Grant, B. F., \& Hasin, D. S. (2012). Stress and alcohol: Epidemiologic evidence. Alcohol Research: Current Reviews, 34(4), 391-400. https://www.ncbi.nlm.nih.gov/pmc/articles/PMC3797525/pdf/arcr-34-4-391.pdf

Knowles, K. A., \& Olatunji, B. O. (2021). Anxiety and safety behavior usage during the COVID-19 pandemic: The prospective role of contamination fear. Journal of Anxiety Disorders, 77 (no pagination). https://doi.org/http://dx.doi.org/10.1016/j.janxdis.2020.102323

Kreslake, J. M., Simard, B. J., O'Connor, K. M., Patel, M., Vallone, D. M., \& Hair, E. C. (2021). E-Cigarette Use Among Youths and Young Adults During the COVID-19 Pandemic: United States, 2020. American journal of public health, 111(6), 1132-1140. https://doi.org/http://dx.doi.org/10.2105/AJPH.2021.306210

Lee, J. (2020). Mental health effects of school closures during COVID-19. The Lancet Child \& Adolescent Health, 4(6). https://doi.org/10.1016/s2352-4642(20)30109-7

Leeb, R. T., Bitsko, R. H., Radhakrishnan, L., Martinez, P., Njai, R., \& Holland, K. M. (2020). Mental Health-Related Emergency Department Visits Among Children Aged $<18$ Years During the COVID-19 Pandemic - United States, January 1-October 17, 2020. Mmwr, Morbidity and mortality weekly report. 69(45), 1675-1680. https://doi.org/http://dx.doi.org/10.15585/mmwr.mm6945a3

Li, H. Y., Cao, H., Leung, D. Y. P., \& Mak, Y. W. (2020). The psychological impacts of a covid19 outbreak on college students in China: A longitudinal study. International Journal of Environmental Research and Public Health, 17(11). https://doi.org/http://dx.doi.org/10.3390/ijerph17113933

Li, S. H., Beames, J. R., Newby, J. M., Maston, K., Christensen, H., \& Werner-Seidler, A. (2021). The impact of COVID-19 on the lives and mental health of Australian adolescents. European Child and Adolescent Psychiatry. https://doi.org/http://dx.doi.org/10.1007/s00787-021-01790-x

Li, Y., Zhao, J., Ma, Z., McReynolds, L. S., Lin, D., Chen, Z., Wang, T., Wang, D., Zhang, Y., Zhang, J., Fan, F., \& Liu, X. (2021). Mental Health Among College Students During the COVID-19 Pandemic in China: A 2-Wave Longitudinal Survey. Journal of Affective Disorders, 281, 597-604. https://doi.org/http://dx.doi.org/10.1016/j.jad.2020.11.109 
Liébana-Presa, C., Martínez-Fernández, M. C., Benítez-Andrades, J. A., Fernández-Martínez, E., Marqués-Sánchez, P., \& García-Rodríguez, I. (2020). Stress, Emotional Intelligence and the Intention to Use Cannabis in Spanish Adolescents: Influence of COVID-19 Confinement. Front Psychol, 11, 582578. https://doi.org/10.3389/fpsyg.2020.582578

Ligus, K., Fritzson, E., Hennessy, E. A., Acabchuk, R. L., \& Bellizzi, K. (2021). Disruptions in the management and care of university students with preexisting mental health conditions during the COVID-19 pandemic. Translational Behavioral Medicine, 11(3), 802-807. https://doi.org/http://dx.doi.org/10.1093/tbm/ibab020

Magson, N. R., Freeman, J. Y. A., Rapee, R. M., Richardson, C. E., Oar, E. L., \& Fardouly, J. (2021). Risk and Protective Factors for Prospective Changes in Adolescent Mental Health during the COVID-19 Pandemic. Journal of youth and adolescence, 50(1), 44-57. https://doi.org/http://dx.doi.org/10.1007/s10964-020-01332-9

Manjareeka, M., \& Pathak, M. (2020). COVID-19 lockdown anxieties: Is student a vulnerable group? Journal of Indian Association for Child and Adolescent Mental Health, 17(1), $72-$ 80. https://jiacam.org/ojs/index.php/JIACAM/article/download/644/352

Mastorci, F., Piaggi, P., Doveri, C., Trivellini, G., Casu, A., Pozzi, M., Vassalle, C., \& Pingitore, A. (2021). Health-Related Quality of Life in Italian Adolescents During Covid-19 Outbreak. Front Pediatr, 9, 611136. https://doi.org/10.3389/fped.2021.611136

Matovu, J. K. B., Kabwama, S. N., Ssekamatte, T., Ssenkusu, J., \& Wanyenze, R. K. (2021). COVID-19 Awareness, Adoption of COVID-19 Preventive Measures, and Effects of COVID-19 Lockdown Among Adolescent Boys and Young Men in Kampala, Uganda. Journal of community health., 22. https://doi.org/http://dx.doi.org/10.1007/s10900-021$\underline{00961-\mathrm{w}}$

Melegari, M. G., Giallonardo, M., Sacco, R., Marcucci, L., Orecchio, S., \& Bruni, O. (2021). Identifying the impact of the confinement of Covid-19 on emotional-mood and behavioural dimensions in children and adolescents with attention deficit hyperactivity disorder (ADHD). Psychiatry Research, 296 (no pagination). https://doi.org/http://dx.doi.org/10.1016/j.psychres.2020.113692

Merline, A. C., P.F., O. M., Schulenberg, J. E., Bachman, J. G., \& Johnston, L. D. (2004). Substance use among adults 35 years of age: prevalence, adulthood predictors, and impact of adolescent substance use. American journal of public health, 94(1), 96-102.

Mohler-Kuo, M., Dzemaili, S., Foster, S., Werlen, L., \& Walitza, S. (2021). Stress and Mental Health among Children/Adolescents, Their Parents, and Young Adults during the First 
COVID-19 Lockdown in Switzerland. Int J Environ Res Public Health, 18(9). https://doi.org/10.3390/ijerph18094668

Munasinghe, S., Sperandei, S., Freebairn, L., Conroy, E., Jani, H., Marjanovic, S., \& Page, A. (2020). The Impact of Physical Distancing Policies During the COVID-19 Pandemic on Health and Well-Being Among Australian Adolescents. Journal of Adolescent Health, 67(5), 653-661. https://doi.org/http://dx.doi.org/10.1016/j.jadohealth.2020.08.008

Nearchou, F., Hennessy, E., Flinn, C., Niland, R., \& Subramaniam, S. S. (2020). Exploring the impact of covid-19 on mental health outcomes in children and adolescents: A systematic review. International Journal of Environmental Research and Public Health, 17(22), 119. https://doi.org/http://dx.doi.org/10.3390/ijerph17228479

Nelson, K. M., Gordon, A. R., John, S. A., Stout, C. D., \& Macapagal, K. (2020). "Physical Sex Is Over for Now": Impact of COVID-19 on the Well-Being and Sexual Health of Adolescent Sexual Minority Males in the U.S. Journal of Adolescent Health, 67(6), 756762. https://doi.org/http://dx.doi.org/10.1016/j.jadohealth.2020.08.027

Nicholas, J., Bell, I. H., Thompson, A., Valentine, L., Simsir, P., Sheppard, H., \& Adams, S. (2021). Implementation lessons from the transition to telehealth during COVID-19: a survey of clinicians and young people from youth mental health services. Psychiatry Research, 299 (no pagination). https://doi.org/http://dx.doi.org/10.1016/j.psychres.2021.113848

Niedzwiedz, C. L., Green, M. J., Benzeval, M., Campbell, D., Craig, P., Demou, E., Leyland, A., Pearce, A., Thomson, R., Whitley, E., \& Katikireddi, S. V. (2021). Mental health and health behaviours before and during the initial phase of the COVID-19 lockdown: longitudinal analyses of the UK Household Longitudinal Study. Journal of epidemiology and community health, 75(3), 224-231. https://doi.org/http://dx.doi.org/10.1136/jech$\underline{2020-215060}$

Nobari, H., Fashi, M., Eskandari, A., Villafaina, S., Murillo-Garcia, A., \& Perez-Gomez, J. (2021). Effect of covid-19 on health-related quality of life in adolescents and children: A systematic review. International Journal of Environmental Research and Public Health, 18(9). https://doi.org/http://dx.doi.org/10.3390/ijerph18094563

Nussbaumer-Streit, B., Klerings, I., Dobrescu, A. I., Persad, E., Stevens, A., Garritty, C., Kamel, C., Affengruber, L., King, V. J., \& Gartlehner, G. (2020, Feb). Excluding non-English publications from evidence-syntheses did not change conclusions: a metaepidemiological study. J Clin Epidemiol, 118, 42-54.

https://doi.org/10.1016/j.jclinepi.2019.10.011 
O'Brien, R. P., Parra, L. A., \& Cederbaum, J. A. (2021). "Trying My Best": Sexual Minority Adolescents' Self-Care During the COVID-19 Pandemic. Journal of Adolescent Health. https://doi.org/http://dx.doi.org/10.1016/j.jadohealth.2021.03.013

Oliveira, W. A., Silva, J. L. D., Andrade, A. L. M., Micheli, D., Carlos, D. M., \& Silva, M. A. I. (2020). Adolescents' health in times of COVID-19: a scoping review. Cadernos de saude publica, 36(8), e00150020. https://doi.org/http://dx.doi.org/10.1590/0102-311x00150020

Owens, J. S., Murphy, C. E., Richerson, L., Girio, E. L., \& Himawan, L. K. (2008, Apr). Science to practice in underserved communities: the effectiveness of school mental health programming. J Clin Child Adolesc Psychol, 37(2), 434-447.

https://doi.org/10.1080/15374410801955912

Page, M. J., McKenzie, J. E., Bossuyt, P. M., Boutron, I., Hoffmann, T. C., Mulrow, C. D., Shamseer, L., Tetzlaff, J. M., Akl, E. A., Brennan, S. E., Chou, R., Glanville, J., Grimshaw, J. M., Hrobjartsson, A., Lalu, M. M., Li, T., Loder, E. W., Mayo-Wilson, E., McDonald, S., McGuinness, L. A., Stewart, L. A., Thomas, J., Tricco, A. C., Welch, V. A., Whiting, P., \& Moher, D. (2021, Mar 29). The PRISMA 2020 statement: an updated guideline for reporting systematic reviews. BMJ, 372, n71. https://doi.org/10.1136/bmj.n71

Palamar, J. J., Le, A., \& Acosta, P. (2021). Shifts in Drug Use Behavior Among Electronic Dance Music Partygoers in New York During COVID-19 Social Distancing. Substance use \& misuse, 56(2), 238-244. https://doi.org/http://dx.doi.org/10.1080/10826084.2020.1857408

Paltell, K. C., Smith, R. L., Kansky, J., Cox, C. M., Amstadter, A. B., Dick, D., The Spit for Science Working, G., Salvatore, J. E., \& Berenz, E. C. (2020, 2020/03/01/).

Posttraumatic stress disorder symptoms, relationship quality, and risky alcohol use among trauma-exposed students. Addictive Behaviors, 102, 106216. https://doi.org/https://doi.org/10.1016/j.addbeh.2019.106216

Panda, P. K., Gupta, J., Chowdhury, S. R., Kumar, R., Meena, A. K., Madaan, P., Sharawat, I. K., \& Gulati, S. (2021). Psychological and Behavioral Impact of Lockdown and Quarantine Measures for COVID-19 Pandemic on Children, Adolescents and Caregivers: A Systematic Review and Meta-Analysis. Journal of Tropical Pediatrics, 67(1). https://doi.org/http://dx.doi.org/10.1093/tropej/fmaa122

Pandor, A., Kaltenthaler, E., Martyn-St James, M., Wong, R., Cooper, K., Dimairo, M., O'Cathain, A., Campbell, F., \& Booth, A. (2019). Delphi consensus reached to produce a decision tool for SelecTing Approaches for Rapid Reviews (STARR) [Article]. Journal of Clinical Epidemiology, 114, 22-29. https://doi.org/10.1016/j.jclinepi.2019.06.005 
Penner, F., Hernandez Ortiz, J., \& Sharp, C. (2021). Change in Youth Mental Health During the COVID-19 Pandemic in a Majority Hispanic/Latinx US Sample. Journal of the American Academy of Child and Adolescent Psychiatry, 60(4), 513-523.

https://doi.org/http://dx.doi.org/10.1016/j.jaac.2020.12.027

Racine, N., Cooke, J. L., Eirich, R., Korczak, D. J., McArthur, B., \& Madigan, S. (2020). Child and adolescent mental illness during COVID-19: A rapid review. Psychiatry Research.

Raviv, T., Warren, C. M., Washburn, J. J., Kanaley, M. K., Eihentale, L., Goldenthal, H. J., Russo, J., Martin, C. P., Lombard, L. S., Tully, J., Fox, K., \& Gupta, R. (2021). Caregiver Perceptions of Children's Psychological Well-being during the COVID-19 Pandemic. JAMA Network Open, 4(4). https://doi.org/http://dx.doi.org/10.1001/jamanetworkopen.2021.11103

Ruff, S. C., \& Linville, D. (2021). Experiences of young adults with a history of foster care during COVID-19. Child Youth Serv Rev, 121, 105836. https://doi.org/10.1016/j.childyouth.2020.105836

Ryerson, N. C., Wilson, O. W. A., Pena, A., Duffy, M., \& Bopp, M. (2021). What happens when the party moves home? The effect of the COVID-19 pandemic on U.S. college student alcohol consumption as a function of legal drinking status using longitudinal data. Translational Behavioral Medicine, 11(3), 772-774. https://doi.org/http://dx.doi.org/10.1093/tbm/ibab006

Savage, M. J., James, R., Magistro, D., Donaldson, J., Healy, L. C., Nevill, M., \& Hennis, P. J. (2020). Mental health and movement behaviour during the COVID-19 pandemic in UK university students: Prospective cohort study. Mental Health and Physical Activity, 19 (no pagination). https://doi.org/http://dx.doi.org/10.1016/j.mhpa.2020.100357

Schwartz-Lifshitz, M., Basel, D., Lang, C., Hertz-Palmor, N., Dekel, I., Zohar, J., \& Gothelf, D. (2021). Obsessive compulsive symptoms severity among children and adolescents during COVID-19 first wave in Israel. Journal of Obsessive-Compulsive and Related Disorders, 28 (no pagination). https://doi.org/http://dx.doi.org/10.1016/j.jocrd.2020.100610

Scott, S., McGowan, V. J., \& Visram, S. (2021). 'I'm Gonna Tell You about How Mrs Rona Has Affected Me'. Exploring Young People's Experiences of the COVID-19 Pandemic in North East England: A Qualitative Diary-Based Study. International Journal of Environmental Research and Public Health, 18(7). https://doi.org/http://dx.doi.org/10.3390/ijerph18073837 
Sharma, P., Ebbert, J. O., Rosedahl, J. K., \& Philpot, L. M. (2020). Changes in substance use among young adults during a respiratory disease pandemic. SAGE Open Medicine, 8(no pagination). https://doi.org/http://dx.doi.org/10.1177/2050312120965321

Singh, S., Roy, D., Sinha, K., Parveen, S., Sharma, G., \& Joshi, G. (2020). Impact of COVID-19 and lockdown on mental health of children and adolescents: A narrative review with recommendations. Psychiatry Research, 293 (no pagination). https://doi.org/http://dx.doi.org/10.1016/j.psychres.2020.113429

Sokolovsky, A. W., Hertel, A. W., Micalizzi, L., White, H. R., Hayes, K. L., \& Jackson, K. M. (2021). Preliminary impact of the COVID-19 pandemic on smoking and vaping in college students. Addictive Behaviors, 115 (no pagination). https://doi.org/http://dx.doi.org/10.1016/j.addbeh.2020.106783

Son, C., Hegde, S., Smith, A., Wang, X., \& Sasangohar, F. (2020). Effects of COVID-19 on college students' mental health in the United States: Interview survey study. Journal of Medical Internet Research, 22(9). https://doi.org/http://dx.doi.org/10.2196/21279

Sprang, G., \& Silman, M. (2013). Posttraumatic Stress Disorder in Parents and Youth After Health-Related Disasters. Disaster Medicine and Public Health Preparedness, 7(1), 105110. https://doi.org/10.1017/dmp.2013.22

Stavridou, A., Stergiopoulou, A. A., Panagouli, E., Mesiris, G., Thirios, A., Mougiakos, T., Troupis, T., Psaltopoulou, T., Tsolia, M., Sergentanis, T. N., \& Tsitsika, A. (2020). Psychosocial consequences of COVID-19 in children, adolescents and young adults: A systematic review. Psychiatry and Clinical Neurosciences, 74(11), 615-616. https://doi.org/http://dx.doi.org/10.1111/pcn.13134

Steffen, J., Schlichtiger, J., Huber, B. C., \& Brunner, S. (2021). Altered alcohol consumption during COVID-19 pandemic lockdown. Nutrition Journal, 20(1). https://doi.org/http://dx.doi.org/10.1186/s12937-021-00699-0

Suhail, A., Iqbal, N., \& Smith, J. (2020). Lived experiences of Indian Youth amid COVID-19 crisis: An interpretative phenomenological analysis. The International journal of social psychiatry, 20764020966021. https://doi.org/http://dx.doi.org/10.1177/0020764020966021

Szajnoga, D., Klimek-Tulwin, M., \& Piekut, A. (2020). COVID-19 lockdown leads to changes in alcohol consumption patterns. Results from the Polish national survey. Journal of Addictive Diseases, 39(2), 215-225. https://doi.org/http://dx.doi.org/10.1080/10550887.2020.1848247 
Tanaka, T., \& Okamoto, S. (2021). Increase in suicide following an initial decline during the COVID-19 pandemic in Japan. Nature human behaviour, 5(2), 229-238. https://doi.org/http://dx.doi.org/10.1038/s41562-020-01042-z

Tavolacci, M. P., Wouters, E., Van de Velde, S., Buffel, V., Dechelotte, P., Van Hal, G., \& Ladner, J. (2021). The impact of covid-19 lockdown on health behaviors among students of a french university. International Journal of Environmental Research and Public Health, 18(8). https://doi.org/http://dx.doi.org/10.3390/ijerph18084346

Teng, Z., Pontes, H. M., Nie, Q., Griffiths, M. D., \& Guo, C. (2021). Depression and anxiety symptoms associated with internet gaming disorder before and during the COVID-19 pandemic: A longitudinal study. Journal of behavioral addictions., 10. https://doi.org/http://dx.doi.org/10.1556/2006.2021.00016

Thorisdottir, I. E., Asgeirsdottir, B. B., Kristjansson, A. L., Valdimarsdottir, H. B., Jonsdottir Tolgyes, E. M., Sigfusson, J., Allegrante, J. P., Sigfusdottir, I. D., \& Halldorsdottir, T. (2021). Depressive symptoms, mental wellbeing, and substance use among adolescents before and during the COVID-19 pandemic in Iceland: a longitudinal, population-based study. The Lancet Psychiatry, 8(8), 663-672. https://doi.org/10.1016/s2215$\underline{0366(21) 00156-5}$

Tucker, J. S., D'Amico, E. J., Pedersen, E. R., Garvey, R., Rodriguez, A., \& Klein, D. J. (2020). Behavioral Health and Service Usage During the COVID-19 Pandemic Among Emerging Adults Currently or Recently Experiencing Homelessness. Journal of Adolescent Health, 67(4), 603-605. https://doi.org/http://dx.doi.org/10.1016/j.jadohealth.2020.07.013

Turner, B. J., Robillard, C. L., Ames, M. E., \& Craig, S. G. (2021, Aug 11). Prevalence and Correlates of Suicidal Ideation and Deliberate Self-harm in Canadian Adolescents During the Coronavirus Disease 2019 Pandemic. Can J Psychiatry, 7067437211036612. https://doi.org/10.1177/07067437211036612

Usher, K., Marriott, R., Smallwood, R., Walker, R., Shepherd, C., Hopkins, K., Skeffington, P., Reid, C., \& Jackson, D. (2020, Oct). COVID-19 and social restrictions: the potential mental health impact of social distancing and isolation for young Indigenous Australians. Australas Psychiatry, 28(5), 599-600. https://doi.org/10.1177/1039856220943018

Valentine, S. E., \& Shipherd, J. C. (2018, Dec). A systematic review of social stress and mental health among transgender and gender non-conforming people in the United States. Clin Psychol Rev, 66, 24-38. https://doi.org/10.1016/j.cpr.2018.03.003 
Vallejo-Slocker, L., Fresneda, J., \& Vallejo, M. A. (2020). Psychological Wellbeing of Vulnerable Children During the COVID-19 Pandemic. Psicothema, 32(4), 501-507. https://doi.org/http://dx.doi.org/10.7334/psicothema2020.218

Wade, M., Prime, H., \& Browne, D. T. (2020, Aug). Why we need longitudinal mental health research with children and youth during (and after) the COVID-19 pandemic. Psychiatry Res, 290, 113143. https://doi.org/10.1016/j.psychres.2020.113143

Walker, R., Usher, K., Jackson, D., Reid, C., Hopkins, K., Shepherd, C., Smallwood, R., \& Marriott, R. (2021). Connection to... addressing digital inequities in supporting the wellbeing of young indigenous australians in the wake of covid-19. International Journal of Environmental Research and Public Health, 18(4), 1-14. https://doi.org/http://dx.doi.org/10.3390/ijerph18042141

Waselewski, E. A., Waselewski, M. E., \& Chang, T. (2020). Needs and Coping Behaviors of Youth in the U.S. During COVID-19. Journal of Adolescent Health, 67(5), 649-652. https://doi.org/http://dx.doi.org/10.1016/j.jadohealth.2020.07.043

White, H. R., Stevens, A. K., Hayes, K., \& Jackson, K. M. (2020). Changes in Alcohol Consumption Among College Students Due to COVID-19: Effects of Campus Closure and Residential Change. Journal of studies on alcohol and drugs, 81(6), 725-730. https://doi.org/http://dx.doi.org/10.15288/jsad.2020.81.725

WHO. (2011). Youth and Health Risks: Report by the Secretariat.

Wu, P., Duarte, C. S., Mandell, D. J., Fan, B., Liu, X., Fuller, C. J., Musa, G., Cohen, M., Cohen, P., \& Hoven, C. W. (2006, May). Exposure to the World Trade Center attack and the use of cigarettes and alcohol among New York City public high-school students. Am J Public Health, 96(5), 804-807. https://doi.org/10.2105/AJPH.2004.058925

Xiang, M., Yamamoto, S., \& Mizoue, T. (2020, May 29). Depressive symptoms in students during school closure due to COVID-19 in Shanghai. medRxiv. https://doi.org/10.1111/pcn.13161

Yang, X., Hu, H., Zhao, C., Xu, H., Tu, X., \& Zhang, G. (2021). A longitudinal study of changes in smart phone addiction and depressive symptoms and potential risk factors among Chinese college students. BMC Psychiatry, 21(1). https://doi.org/http://dx.doi.org/10.1186/s12888-021-03265-4

Zhang, L., Zhang, D., Fang, J., Wan, Y., Tao, F., \& Sun, Y. (2020). Assessment of Mental Health of Chinese Primary School Students before and after School Closing and Opening 
during the COVID-19 Pandemic. JAMA Network Open, 3(9).

https://doi.org/http://dx.doi.org/10.1001/jamanetworkopen.2020.21482

Zhou, S. J., Zhang, L. G., Wang, L. L., Guo, Z. C., Wang, J. Q., Chen, J. C., Liu, M., Chen, X., \& Chen, J. X. (2020, Jun). Prevalence and socio-demographic correlates of psychological health problems in Chinese adolescents during the outbreak of COVID-19. Eur Child Adolesc Psychiatry, 29(6), 749-758. https://doi.org/10.1007/s00787-020-01541-4

Zijlmans, J., Teela, L., van Ewijk, H., Klip, H., van der Mheen, M., Ruisch, H., Luijten, M. A. J., van Muilekom, M. M., Oostrom, K. J., Buitelaar, J., Hoekstra, P. J., Lindauer, R., Popma, A., Staal, W., Vermeiren, R., van Oers, H. A., Haverman, L., \& Polderman, T. J. C. (2021). Mental and Social Health of Children and Adolescents With Pre-existing Mental or Somatic Problems During the COVID-19 Pandemic Lockdown. Front Psychiatry, 12, 692853. https://doi.org/10.3389/fpsyt.2021.692853

Znazen, H., Slimani, M., Bragazzi, N. L., \& Tod, D. (2021). The relationship between cognitive function, lifestyle behaviours and perception of stress during the covid-19 induced confinement: Insights from correlational and mediation analyses. International Journal of Environmental Research and Public Health, 18(6), 1-12.

https://doi.org/http://dx.doi.org/10.3390/ijerph18063194 

